ISSN 1676-3742

\title{
Teologia Pública e o conceito de "fronteira" no pensamento de Paul Tillich
}

\author{
Carlos Alberto Motta Cunha
}

\section{Resumo}

Pensar a teologia pública, especificamente no âmbito epistemológico, a partir do conceito de "fronteira" de Tillich é colocar a teologia pública numa zona de "encontro" para experimentar algo, sobretudo novo. Esse "algo novo" advém, no caso do Brasil, de uma situação nova em que a teologia se encontra perante a academia, a igreja e a sociedade. O método da correlação, de Paul Tillich, tem como locus o lugar de fronteira (boundary-situation), que perpassa toda a teologia sistemática tillichiana e pretende explicar os conteúdos da fé através de perguntas e respostas teológicas em interdependência mútua. Só há possibilidade de fronteira na abertura provocada pela situação. O próprio termo "correlação" já comporta em si mais de uma possibilidade. O vocábulo ocupa, assim, um lugar de prestígio na comunicação acadêmica, eclesial e social, pois abre caminho para expressar a relação entre conceitos, ideias e pensamentos que podem ser totalmente diferentes.

Palavras-chave: Teologia Pública, Paul Tillich, Fronteira.

\section{Abstract}

To think of public theology, especifically in the epistemological context, starting from Tillich's idea of "boundary", is to place public theology in the area of "encounter" in order to experience something, especially something new. This "new something" comes, in the case of Brazil, from a new situation 
in which theology finds itself facing the academy, the church and society. Paul Tillich's method of correlation has as its setting a boundary place (boundarysituation) which pervades all Tillich's systematic theology and seeks to explain the contents of faith by means of theological questions and answers in mutual interdependence. So there is the possibility of boundary in the opening caused by the situation. The very term "correlation" already suggests more than one possibility. The vocabulary thus occupies a place of prestige in academic, ecclesial and social communication because it opens the way to express a relation among concepts, ideas and thoughts which could be totally different.

Keywords: Public Theology, Paul Tillich, Boundary.

\section{Introdução}

O alvo de interesse desta comunicação consiste em demonstrar como a epistemologia teológica, i.é., o seu estatuto teórico-teológico próprio, pensada a partir do método da correlação de Tillich (no conceito de "fronteira") pode contribuir para a legitimidade da teologia no âmbito público no Brasil. Assim, não se pretende fazer uma abordagem pormenorizada da teologia pública e nem uma avaliação da teologia sistemática de Paul Tillich. O que interessa em Tillich é o método da correlação pensado a partir do conceito de "fronteira" e como ele orienta a sua teologia. Quanto à teologia pública, o lugar de interesse consiste no estatuto teórico-teológico.

Esse "encontro" acontece dentro de um referente: o contexto brasileiro. $\mathrm{O}$ foco do texto gira em torno da problemática que a teologia se encontra no Brasil, a saber, diante da legitimidade do seu trânsito entre os espaços fronteiriços - sociedade, igreja e academia.

\section{Teologia pública}

Excetuando alguns casos localizados, de um modo geral, a teologia foi excluída do rol das ciências legítimas dos tempos modernos. As universidades que a conservaram o fizeram em nome de acordos entre as Igrejas e o Estado, caso emblemático da Alemanha. A teologia permanece, portanto, no seio da universidade como um conhecimento entre os demais, porém sob a responsabilidade das Igrejas e do Estado. Enquanto este a sustenta financeiramente, aquelas 
sustentam a sua confessionalidade. A legitimidade do conhecimento teológico deslocou-se, portanto, da esfera epistemológica para a esfera do político.

$\mathrm{Na}$ Itália, por exemplo, as faculdades de Teologia nas universidades públicas foram dissolvidas em 1873. De lá até hoje, nas universidades públicas da Itália só existem disciplinas ou programas de Ciências da Religião. A teologia está reclusa aos numerosos Institutos Superiores de Estudos Religiosos destinados aos leigos que estudam teologia para darem aula de religião nas escolas públicas de primeiro e segundo grau pago pelo governo. Lembrando que a aula de religião é facultativa.

Outro contexto que prova a rejeição da teologia enquanto ciência encontra-se em Portugal. De uma forte presença do religioso nos inícios do século XX passamos a um esquecimento e até a um quase abandono deste espaço. As instituições religiosas, responsáveis por grande parte da formação intelectual, vão cedendo seu lugar a instituições seculares. Com a saída da faculdade de Teologia da Universidade de Coimbra, acentua-se em definitivo que este estudo deve ficar restrito às fileiras internas das Igrejas, servindo para a formação de seus clérigos ou agentes religiosos.

Com efeito, no decorrer dos tempos modernos a teologia se tornou cada vez mais "coisa de Igreja", restrita aos muros eclesiais e destinada ao consumo interno dos sujeitos religiosos. Seu caráter acadêmico e público vai perdendo a visibilidade, enquanto as ciências ganham força e se institucionalizam no âmbito das universidades, nas suas mais variadas especializações e aplicações técnicas.

Mesmo admitindo certa legitimidade ao religioso, enquanto opção individual inscrita no âmbito dos valores que não devem interferir no exercício da razão, a comunidade científica dispensa a teologia de suas buscas e atividades interdisciplinares. Assim é que a teologia encontra-se hoje em uma situação ambígua, em termos de sua legitimidade epistemológica.

A teologia pública busca ser uma contribuição de comunidades religiosas nas sociedades democráticas plurais e da teologia acadêmica que sobre elas reflete, crítica e autocriticamente, para o debate público. É uma falácia pensar que a teologia pública visa estabelecer uma teocracia. Igualmente falacioso é achar também que a teologia pública busca uma secularização dos conceitos teológicos por dentro da política (teologia política).

Então o que busca? A teologia pública procura ser uma teologia separada do âmbito da política, sem ser alienada, num estado secular de direito, que reconhece plenamente a liberdade religiosa e no qual ela procura contribuir como parceira crítico-construtiva para o bem comum. Para isso, assume o seu caráter acadêmico, plural e interdisciplinar. 
No Brasil, na década de 60, houve um esforço em dar um caráter público à teologia. $\mathrm{O}$ antropólogo Darcy Ribeiro foi pioneiro nesse intento. Embora fosse um agnóstico, ele queria criar um curso de Teologia dentro da universidade, mas seu intento foi frustrado pelo regime militar. É evidente que a compreensão que, nesse caso, ele tinha da teologia, se aproximava mais à de ciência da religião.

Estabelecer a distinção entre teologia e ciência da religião ${ }^{1}$ é importante para uma compreensão da teologia pública. A teologia assume uma tradição religiosa específica e se permite, além da abordagem descritiva, também propor reflexões quanto à pertinência normativa do assunto em pauta. Já a ciência da religião é, por natureza, descritiva e deve ser comparativa, ou seja, ter em vista mais de uma religião.

Mesmo praticada cientificamente, como disciplina universitária, a teologia ainda está, em todo caso, ligada ao fenômeno "igreja". Portanto, não é devido à especificidade dos seus métodos que a teologia se diferencia da ciência da religião e de outras ciências sociais, mas, por certo, através de sua função "social" e, com isso, através de sua realidade passível de descrição social. Com efeito, a teologia é um ato de tomada de consciência da igreja sobre si mesma. $\mathrm{O}$ aspecto especificamente teológico desse ato é, antes, sua função ligada à igreja.

No mundo anglo-saxão e, mais recentemente, na Alemanha, procura-se fazer uma ponte entre a teologia e a ciência da religião mediante a chamada "teologia comparativa" (comparative theology). No Brasil, ainda que a teologia seja identificada com determinada confissão religiosa, ela não se restringe a esta, mas procura construir pontes com outras confissões, religiões e ciências, bem como com a sociedade mais ampla. Percebe-se esta verdade na elaboração metodológica do tripé ver-julgar-agir da teologia da libertação e no seu intenso diálogo com as ciências sociais. Na atualidade, o fazer teológico no Brasil intensificou o seu diálogo com a ciência da religião.

É na interlocução entre as confissões, religiões e ciências que David Tracy legitima o lugar da teologia pública, atendendo, do seu modo específico, aos públicos da academia, da Igreja e da sociedade. O mesmo faz Jürgen Moltmann, ao tratar sobre os lugares da existência teológica - lugares intramundanos que alimentam o fazer teológico a partir da experiência na e com a vida.

\footnotetext{
${ }^{1} \mathrm{O}$ termo "ciência da religião" é cambiante. No Brasil, há quatro possibilidades de conceituação do termo: ciência da religião, ciências da religião, ciências das religiões, ciência das religiões.
} 
Mas a busca por legitimidade da teologia no contexto brasileiro não é tão simples assim. Devido à lentidão histórica da teologia no Brasil, causada por retraimentos social, científico e político, a busca por cidadania acadêmica por parte da teologia esbarra em três carências constitutivas: primeira, a carência de legitimidade epistemológica dentro da comunidade científico-acadêmica. Por ser taxada como "coisa de igreja", a teologia sofre de "suspeita ideológica", como conhecimento ligado aos interesses políticos das Igrejas e, portanto, danoso para a sociedade plural e laica.

Segunda, a carência de legitimidade política, por ficar fora das polêmicas educacionais do ensino superior. A legalização tardia da teologia, em 1999, associada à falta de tradição acadêmica e à fragilidade epistemológica do escopo conceitual dos Pareceres 241/99 e 63/04, favorecem um status da teologia como subárea das ciências humanas².

Terceira, a carência de legitimidade cultural, provocada pelo confinamento da teologia à esfera eclesial. A teologia ainda se mostra como desconhecida da população de um modo geral e soa estranha como curso superior legalmente reconhecido, até mesmo em ambientes acadêmicos.

Apesar dessas carências, a presença acadêmica e social da teologia nas universidades e faculdades, a partir de seu reconhecimento legal, lançou-a, ainda que incipientemente, no espaço público e, portanto, numa zona ambígua, onde ela é vista como "coisa de igreja" em tensão com "coisa pública". Esse desígnio, provavelmente insuperável pela própria natureza da teologia, tenderá a buscar caminhos de legitimação pública da teologia.

A título de exemplo, citaremos pelo menos quatro caminhos possíveis e necessários para a legitimação pública da teologia: 1) no âmbito acadêmico, em diálogo com outros campos do saber; 2) no âmbito político, em diálogo com as problemáticas educacionais; 3) no âmbito religioso, em diálogo com os vários sistemas religiosos, em busca de uma ética global e paz mundial; e, por fim, 4) no âmbito teológico, isto é, seu estatuto epistemológico enquanto saber científico no espaço público.

É sobre este último caminho, âmbito teológico, que esta comunicação propõe estudar a teologia pública no Brasil. Para tal, utilizará a contribuição epistemológica de Paul Tillich como chave hermenêutica para a discussão da teologia pública no contexto brasileiro.

\footnotetext{
${ }^{2} \mathrm{Na}$ "árvore do conhecimento" estabelecida pelo CNPq, a Teologia encontra-se no rol das ciências humanas como subárea da Filosofia.
} 
Mas por que Paul Tillich? O que há de relevante na epistemologia desenvolvida por ele? Como se constrói sua teologia? O que o método desenvolvido por Tillich tem a dizer no contexto brasileiro? Vejamos então a relevância do pensamento de Tillich para a teologia pública no Brasil.

\section{O conceito de "fronteira" em Paul Tillich}

A divisão da trajetória biográfica, intelectual e espiritual de Paul Tillich em dois períodos, alemão (1886-1933) e americano (1933-1965), continua marcada por sua emigração. Tillich é considerado "teólogo da fronteira". É mais do que estar na linha fronteiriça entre dois continentes, mas, ao mesmo tempo, estar entre os mundos, entre os tempos, estar em tensão e em movimento, pensar não em monólogos, mas em diálogo. A teologia de fronteira de Tillich evidencia-se, sobretudo, na relação que ele institui entre religião e cultura secular, e, no método de correlação, constantemente praticado em sua teologia sistemática.

Sua contribuição epistemológica, sintetizada no método da correlação, consiste em estabelecer uma ponte razoável e autêntica entre a fé, a revelação cristã e a cultura moderna. Para este fim desenvolveu o "método da correlação", segundo o qual o conteúdo da revelação cristã se apresenta e demonstra como resposta às perguntas cruciais que brotam da existência do ser humano na modernidade. A teologia querigmática (Barth) leva em conta apenas o anúncio (querigma), sem olhar o outro pólo (destinatário), representado por todas as várias formas culturais que exprimem a interpretação da existência por parte do homem moderno. Daí nasce o projeto tillichiano de completar a "teologia querigmática" com uma teologia apologética, ou seja, uma "teologia que-dá-repostas" (answering theology).

O uso do método da correlação é uma opção pela fronteira entre perguntas e respostas. É preciso ouvir as perguntas para formular respostas. Sem a situação, não há perguntas. Numa época como a nossa, tão cheia de demandas, a teologia necessita ouvir atentamente o grito de uma sociedade plural que anseia por orientação.

No pensamento de Tillich, a "fronteira" (boundary) é chave hermenêutica de sua vida e teologia, a saber, a reivindicação do espaço de fronteira entre

\footnotetext{
${ }^{3}$ Para Tillich, "frontier" e "boundary" não são sinônimos. Enquanto "frontier" assinala os limites, o ponto onde se esgota as possibilidades, "boundary" aponta para o lugar ideal para se desfrutar de novas potencialidades.
} 
diferentes saberes e possibilidades. Estar na fronteira consiste em estar numa posição frutífera para o pensamento.

No ensaio On the Boundary, Tillich deixa transparecer o lugar privilegiado da situação de fronteira (boundary-situation) na aquisição do conhecimento: "A fronteira é o melhor lugar para a aquisição de conhecimento" (TILLICH, 1966, p.13).

Uma situação de fronteira se dá quando a possibilidade humana alcança seu limite, quando a existência humana é confrontada pela ameaça última. Segundo o próprio Tillich, em The Future of the Religions, a "existência na fronteira, em uma situação de limite, é cheia de tensão e movimento. Não é estática, mas, ao contrário, é uma travessia e retorno, uma repetição de retorno e travessia, um vai-e-vem, cujo objetivo é criar uma terceira área além dos limites territoriais, uma área onde se pode permanecer por um tempo sem ser encerrado em algo hermeticamente limitado" (TILLICH, 1966, p.53).

Pensar a teologia pública, especificamente no âmbito epistemológico, a partir do conceito de "fronteira" de Tillich é colocar a teologia pública numa zona de "encontro" (Tillich não utiliza o termo "diálogo" e, sim, "encontro" encounter) para experimentar algo, sobretudo novo. Esse "algo novo" advém, no caso do Brasil, de uma situação nova em que a teologia se encontra perante a academia, a igreja e a sociedade.

O método da correlação, que tem como locus o lugar de fronteira (boundary-situation), perpassa toda a teologia sistemática de Tillich e pretende explicar os conteúdos da fé através de perguntas e respostas teológicas em interdependência mútua. Só há possibilidade de fronteira na abertura provocada pela situação. O próprio termo "correlação" já comporta em si mais de uma possibilidade. O vocábulo ocupa, assim, um lugar de prestígio na comunicação acadêmica, eclesial e social, pois abre caminho para expressar a relação entre conceitos, ideias e pensamentos que podem ser totalmente diferentes.

Um dos grandes expoentes da teologia pública, David Tracy, concorda que o modo de investigação que Tillich veio a conceber a partir de sua correlação é o que mais precisa ser recuperado hoje em dia.

É inegável o papel social da religião quando se trata de refletir sobre temas urgentes no âmbito da política, da cidadania e da bioética. São temas que pedem uma reflexão profunda por parte da teologia cristã. A teologia pública lança à teologia cristã o desafio de ser uma contribuição religiosa crítico-construtiva a tais debates. 
A teologia encontra-se hoje, de modo particular no caso do Brasil, em uma situação ambígua, ou nas palavras de Tillich, numa "situação de fronteira" (boundary-situation), em termos de sua legitimidade como conhecimento. Embora inserida no âmbito das chamadas ciências humanas, a teologia ainda carece, como foi assinalado, de legitimidade epistemológica como conhecimento que se mostra fundamento, viável e relevante por força de seu acúmulo histórico e estruturação teórica e metodológica.

A tensão entre "coisa de igreja" e "coisa pública" é intermediada por um lugar fronteiriço que permite a teologia se situar entre (between - palavra importante no método tillichiano) a confessionalidade e a pluralidade de convicções da sociedade.

É exatamente nesta tensão que o método tillichiano se justifica. O método da correlação pressupõe mensagem e situação. A fronteira surge em virtude da situação, que está carregada de todas as peculiaridades que desafiam a mensagem.

Em termos práticos, pretende-se deixar a teologia (mensagem) ser interpelada pelos dilemas atuais (situação). Estamos diante de uma "coisa de igreja" que se tem mostrado incapaz de se impor, não apesar dessa situação, mas a partir dessa condição, como “coisa pública”. Será preciso resgatar a especificidade da teologia como ciência (conhecimento). O fato de constituir um logos específico exige não mais que a colocação dos fundamentos dessa especificidade, que inclui, evidentemente, referências confessionais, mas, antes disso, a referência da razão que afirma conhecer de modo relacionado à fé.

O lugar de fronteira é propício para refletir a partir de dois horizontes: do horizonte da fé, instituída em conteúdos objetivos no seio da confessionalidade religiosa, advém boa parte da matéria-prima para a reflexão teológica; do horizonte comum da razão lógica e investigativa, instituída em métodos e teorias, advêm as regras do jogo do conhecimento, tanto quanto em outras áreas.

É relevante para a teologia a construção da legitimidade epistemológica diante de outros campos do saber. A teologia deverá conquistar sua cidadania plena como conhecimento dentre os demais que se apresentam ao Ministério da Educação (MEC) como consistente e relevante a serem oferecidos à sociedade e aderem ao jogo institucional das instâncias responsáveis por sua legislação e gestão.

Desde o reconhecimento do curso de Teologia pelo MEC no Brasil, em 1999, e os sucessivos Pareceres com o intuito de regularização do curso, a teologia tem a oportunidade de estabelecer a sua natureza identitária e a sua 
relevância. Cito como exemplo o parecer CNE/CES 118/094, aprovado em 6 de maio de 2009. Entre outras coisas, o Parecer propõe seis eixos para os currículos dos cursos de Teologia:

1. Eixo filosófico - que contemple disciplinas que permitam avaliar as linhas do pensamento subjacentes às Teologias, conhecer as suas bases epistemológicas e desenvolver o respeito à ética.

2. Eixo metodológico - que garanta a apropriação de métodos e estratégias de produção do conhecimento científico na área das Ciências Humanas.

3. Eixo histórico - que garanta a compreensão dos contextos culturais e históricos.

4. Eixo sociológico - que contemple análises sociológicas, econômicas e políticas e seus efeitos nas relações institucionais e internacionais.

5. Eixo linguístico - que possibilite a leitura e a interpretação dos textos que compõem o saber específico de cada Teologia e o domínio de procedimentos da hermenêutica.

6. Eixo interdisciplinar - que estabelece diálogo com áreas de interface, como a Psicologia, a Antropologia, o Direito, a Biologia e outras áreas científicas.

É interessante notar duas coisas aqui nesse parecer: primeiro, o estranhamento diante de um parecer voltado para a área teológica não ter um "eixo teológico" - constituído pelas disciplinas teológicas segundo cada tradição, e, segundo, como esses eixos favorecem o método de correlação proposto por Paul Tillich. São eixos de fronteira! Abrem caminho para a relação entre conceitos, ideias e pensamentos. Os eixos permitem que a teologia transite pelas esferas da academia, igreja e sociedade com o status de teologia pública.

Mas esse trânsito não é infrutífero. Pelo contrário. Ao transitar pelas esferas da academia, da igreja e da sociedade, a teologia re-significa a sua linguagem, seus conceitos e seus tratados com o intuito de ser uma "teologia que-dá-respostas" no espaço público.

\footnotetext{
${ }^{4}$ Embora o parecer CNE/CES 118/09 esteja superado, a sua utilização aqui tem uma função ilustrativa com o intuito de exemplificar a importância da fronteira no diálogo entre a Teologia e os outros campos do saber.
} 


\section{Conclusão}

No Brasil, a discussão sobre a legitimidade da teologia na esfera pública está em alta. São muitas as contribuições vindas dos programas de pós-graduação em Teologia e Ciências da Religião. São dezoito programas de pós-graduação recomendados pela Capes e, desde 2007, vem-se reunindo a Associação Nacional dos Programas de Pós-Graduação em Teologia e Ciências da Religião (ANPTECRE). Além da Anptecre, há aportes provenientes da Sociedade de Teologia e Ciências da Religião (SOTER) e publicações de pesquisas sobre a teologia pública da Escola Superior de Teologia (EST), da Universidade do Vale do Rio dos Sinos (UNISINOS) e dos vários simpósios de Teologia e Ciências da Religião promovidos pelas Pontifícias Universidades Católicas (PUC-RIO, PUC-SP e PUC-RS).

As contribuições oferecidas por estas instituições registram, cada qual com o seu olhar específico, sobretudo o momento que estamos vivendo no Brasil, na busca da institucionalização plena da teologia, seja como área de conhecimento, seja como curso superior.

$\mathrm{O}$ futuro da teologia na vida acadêmica nacional dependerá em muito de sua capacidade de fazer-se legítima dentro da sociedade contemporânea. A teologia é desafiada a demonstrar sua capacidade de dialogar com as ciências na busca da verdade e afirmar sua especificidade metodológica e sua função pública como conhecimento apto a discernir a realidade.

Com o intuito de resgatar a legitimidade epistemológica da teologia enquanto saber no/para o espaço público, é que este estudo engendra a legitimidade epistemológica da teologia pública no Brasil a partir do contributo do conceito de "fronteira" importante no método da correlação de Paul Tillich.

\section{Referências Bibliográficas}

MOLTMANN, Jürgen. Experiências de reflexão teológica: caminhos e formas da teologia cristã. São Leopoldo: Unisinos, 2004.

MORI, Geraldo de; CRUZ, Eduardo Rodrigues da. (Orgs.). Teologia e ciências da religião: a caminho da maioridade acadêmica no Brasil. São Paulo: Paulinas, 2011.

MUELLER, E.R.; BEIMS, R. (Orgs.) Fronteiras e interfaces: o pensamento de Paul Tillich em perspectiva interdisciplinar. São Leopoldo: Sinodal, 2005. 
SOARES, A.M.L.; PASSOS, J.D. Teologia e ciência: diálogos acadêmicos em busca do saber. São Paulo: Paulinas, 2008.

(Orgs.). Teologia pública: reflexões sobre uma área de conhecimento e sua cidadania acadêmica. São Paulo: Paulinas, 2011.

TILLICH, Paul. Theology of culture. Nova Iorque: Oxford University Press, 1959. . On the boundary: an autobiographical sketch. Londres: Collins, 1967. . The future of religions. Nova Iorque: Harper\& How Publishers, 1966. . Teologia sistemática. Trad. Getúlio Betelli e Geraldo Korndörfer. 5.ed. São Leopoldo: Sinodal, 2005.

TRACY, David. A imaginação analógica: a teologia cristã e a cultura do pluralismo. São Leopoldo: Unisinos, 2004.

Carlos Alberto Motta Cunha

Doutorando em Teologia pela Faculdade Jesuíta de Filosofia e Teologia (FAJE), Bolsista da CAPES e integrante do grupo de pesquisa Fé e Contemporaneidade do CNPq.

Artigo Recebido em 23/08/2011 Artigo Aprovado em 30/11/2011 